\title{
The Impact of Children's Academic Competencies and School Grades on their Life Satisfaction: What Really Matters?
}

\section{Jacqueline Lettau ${ }^{1}[0$}

Accepted: 12 May 2021 /Published online: 14 July 2021

(c) The Author(s) 2021

\begin{abstract}
Increasing demands in schools, higher pressure on children's performance levels, and increasing mental health constraints raise questions about the impact of educational achievement on children's life satisfaction. Therefore, this study investigates whether children's academic competence levels and school grades affect their life satisfaction and if the effects vary by educational track. Complementing prior research, this study firstly uses fixed effects regressions to get closer to the estimation of the causal link between children's academic competencies, school grades, and life satisfaction by eliminating time-constant confounding factors such as intelligence, early background characteristics, and genetic factors. By using valuable longitudinal data on academic competencies, school grades, and life satisfaction of children from a sample of 5th-grade students $(N=3045)$ of the National Educational Panel Study in Germany (NEPS) from 2010 to 2015 this study reaches also a broader external validity than prior research. Including various tracks, makes testing for heterogeneous effects by school track attended possible. Results indicate that, on average, children's school grades seem to be highly important for their life evaluations. Moreover, the effect of school grades does not vary across educational tracks, i.e. school grades seem to matter for all children. In contrast, levels of academic competencies seem to be relevant only for specific subgroups. Investigating effect heterogeneities reveals that only among children in the lower secondary school tracks higher competencies are related to lower life satisfaction. Overall, the study highlights the importance of school grades and point out variation in the relevance of competence levels between school tracks.
\end{abstract}

Keywords Children - Academic competence $\cdot$ School grades · Life satisfaction · Fixed effects panel regression $\cdot$ Secondary school tracks

Jacqueline Lettau

jacqueline.lettau@lifbi.de

1 Leibniz Institute for Educational Trajectories (LIfBi), Wilhelmsplatz 3, 96047 Bamberg, Germany 


\section{Introduction}

High levels of mental health problems around the world are one of the most serious challenges in modern societies and about $50 \%$ of mental health problems in adulthood can be attributed to childhood and early adolescence (World Health Organization, 2018, 2019). Especially lower levels of life satisfaction and feelings of unhappiness in childhood are associated with a higher risk of later life mental illness (Gilman \& Huebner, 2003; Park, 2004). Thus, an increasing number of studies investigate early inequalities in children's life satisfaction and ask for valuable strategies for enhancing their emotional well-being to prevent longstanding inequalities in individual mental health (Gilman \& Huebner, 2003). As a result, various strategies for increasing individual life satisfaction are discussed, with early investments in education often seen as the most favorable ones (for review see Powdthavee et al., 2015).

For children, schooling coincides with periods of emotional upheavals, biological and neurobiological changes, as well as social development. Increasing levels of school-related stressors are assumed to interfere with developmental changes and the increasing demands on children's educational achievement and higher pressure in schools result in lower levels of children's life satisfaction and a higher number of mental health constraints (Gilman \& Huebner, 2003; Hascher et al., 2018).

Thus, investigating the effect of children's educational achievement on their life satisfaction might help to address early inequalities in their well-being and mental health outcomes. To investigate the effect of early educational achievement on life satisfaction in children, empirical studies mainly focus on academic competencies and school grades (e.g. Chen \& Lu, 2009; Edgar et al., 2015; González et al., 2020; Lyons \& Huebner, 2016; Rathmann et al., 2018; Suldo et al., 2008). Both concepts indicate one's performance in school, are related to predefined goals within educational settings and directly refer to the whole process of schooling (Smith, 1995). However, although students' actual academic competence levels and school grades are part of the same construct, they often show differences because they include different aspects of achievement evaluations. On the one hand, children's competence levels refer to the actual level of skills and knowledge acquired in education. They indicate how much children have learned in a given subject (Willingham et al., 2002). On the other hand, school grades rather reflect teachers' evaluations of the performance level of children in school. They serve as a signal of recognition of achievement and, although they reflect differences in competence levels, they usually include an assessment of children's behavior in and outside the classroom, their perceived motivation, and individual as well as background characteristics (Lekholm \& Cliffordson, 2008; Willingham et al., 2002). Thus, children's levels of academic competence should affect their school grades, but grades do not automatically represent differences in children's competencies since grades also depend on children's behavior and learning motivation (Steinmayr \& Meißner, 2013).

Differences in the effect on life satisfaction could result from differences in the perceived relevance of school-related competence levels and school grades 
for educational success. Whereas the actual levels of academic competencies are rather unknown for children, school grades are important indicators for performance levels. School grades directly represent feedback on children's school performance and convey the increasing performance expectations placed on children. Getting bad grades could implicitly signal failure in school and create fears about one's future opportunities. Thus, school grades might be of higher relevance in children's' life evaluation because better grades are perceived as important indicators for their success in education. Moreover, there might be theoretical guided interdependencies between both which have not yet been considered.

In empirical research, results regarding the associations between academic competencies, school grades, and children's life satisfaction are mixed. Depending on the cultural context, age group studied, and the level of education, studies show positive and negative associations as well as the lack of correlations. For instance, students' academic competencies are positively associated with general happiness among 11th graders in Taiwan (Chen \& Lu, 2009), with global life satisfaction in seventh and eighth graders in middle schools in the southeastern United States (Lyons \& Huebner, 2016), and with higher life satisfaction among 10- to 19-year-old children in boarding schools in Australia (Martin et al., 2014). In contrast, Bradley and Corwyn (2004) find negative associations in a sample of 10- to 15-year-old children in a small county in the United States. For children's school grades, González et al. (2020) highlight that higher previous-year grade point averages are linked to higher life satisfaction among 13-year-old children in Chile. Additionally, Edgar et al. (2015), Rathmann et al. (2018), Reysen et al. (2017), and $\mathrm{Ng}$ et al. (2015) show that better grades are related to higher levels of life satisfaction of children in different age groups in New Zealand, Germany, and the United States. In contrast, MacCann et al. (2012) did not find any statistically significant association in the U.S.

Although the existing studies provide important and interesting insights into this research topic, some limitations will be addressed in this study. First, given that results on academic competencies and school grades stem from different studies or different regression models, it is difficult to compare the effects of children's academic competencies and school grades on life satisfaction. While these studies provide interesting insights into either the effects of competence levels or school grades, there is still a need for a study design that provides for both estimating and comparing the effects of competencies and school grades in a joint study. Second, previous research is mostly based on cross-sectional designs or employ structural equation models based on panel data, which render it difficult to conclude the causality of the relationship between children's academic competence levels and school grades and their life satisfaction (e.g. Chen \& Lu, 2009; Gilman \& Huebner, 2006; MacCann et al., 2012; Martin et al., 2014; Ng et al., 2015; Reysen et al., 2017; Suldo et al., 2008). Identification in these studies is based on the strict assumption of selection on observed factors. Hence, biases may occur if there are unobserved confounding variables such as intelligence, early background characteristics, and genetic factors, which may occur due to data limitations. In contrast, a longitudinal study with repeated measures of academic competencies, school grades, and life satisfaction and using fixed-effects regressions would allow eliminating time-constant unobserved confounding variables (Brüderl \& Ludwig, 2014). This offers better 
opportunities to make estimates that are closer to the true causal effect. However, it must be emphasized that also fixed-effects regressions can still be biased if there are unobserved time-varying confounding variables. Third, previous studies are mainly based on specific subgroups that generate a high variation in estimation results about the relationship between education and life satisfaction based on sample characteristics. For example, there are studies on special samples such as university students (e.g. Grunschel et al., 2016; Schmitt et al., 2008), higher secondary school students (e.g. Edgar et al., 2015; Reysen et al., 2017; Suldo et al., 2008), students in only small districts (e.g. Bradley \& Corwyn, 2004) or special schools and programs (e.g. Martin et al., 2014). These sample differences can be one explanation for the variation in findings across studies. A limitation of these subgroup-specific studies is that no general conclusion about the link between children's academic competence levels, school grades and life satisfaction can be drawn, and comparisons between subgroups are not possible.

Against this background, I investigate the effect of children's academic competence levels and school grades on life satisfaction. The present paper tries to fill the research gaps in the existing literature described above in several ways. First, instead of just focusing on either academic competencies or school grades this study analyzes the effects of both as well as differentiate between competence levels in reading and math. This allows for a comparison of the effects of academic competencies and grades on life satisfaction in one study design. Second, the study addresses data limitations of previous research by deploying prospective panel data from the German National Educational Panel Study (NEPS) on educational trajectories of students in secondary school. The NEPS includes reliable repeated measures of children's skill levels through validated standardized tests, which identify core components of competencies and allow linkage between test scores across panel waves (Weinert et al., 2011), school grades, life satisfaction, and other background characteristics. To get closer to the true causal effect than previous studies, this study uses the advantages of the panel data by deploying fixed-effects regression models to eliminate time-constant unobserved confounding variables. Finally, regarding the issue of external validity, this study includes students from various secondary school tracks and not only selective subgroups. This contributes to the scarce literature investigating broad samples and heterogeneity in the effect of children's competence levels and grades on their life satisfaction (e.g. Nordlander \& Stensöta, 2014). Thus, I test for effect heterogeneity, i.e. to investigate whether the effects of competencies and grades on life satisfaction differ between the school tracks attended.

\section{Theoretical Considerations and Hypotheses}

\subsection{The Effect of Children's Competence Levels and School Grades on Life Satisfaction}

To answer the question of how children's levels in academic competencies and school grades affect their life satisfaction the literature provides various theories, which consider economic and psychological approaches and stress different theoretical 
mechanisms. In the following, I focus on arguments of the human capital theory but complement the theoretical arguments with explanations of the psychological theory of self-determination to consider also psychological processes (Grossman, 2006; Ryan \& Deci, 2000).

From both perspectives, children's levels of academic competence should enhance their life satisfaction, because they are assumed to represent individuals' skills and knowledge levels acquired in education. Higher levels of skills and knowledge are assumed to enhance children's life satisfaction, firstly, because they increase children's abilities to manage highly demanding tasks and being able to adapt to changing external or internal demands resulting in better coping with stressful life events (Grossman, 2006; Smith \& Carlson, 1997). This prevents emotional or behavioral problems and, thus, avoids negative consequences on children's life satisfaction caused by external stressors (Smith \& Carlson, 1997). Secondly, higher skills and knowledge enhance children's life satisfaction, because they foster children's abilities to use given resources, e.g. pocket money, more efficiently (Grossman, 2006). This allows higher quality and quantity of investments in relevant means producing life satisfaction, like going to the cinema, buying treats, or important clothes and toys. Thirdly, higher skills and knowledge levels enable children to choose positive input and avoid the negative to enhance their life satisfaction levels. Thus, children with higher skills and knowledge levels tend to avoid early health-damaging behavior, like smoking and excessive alcohol consumption, participate more often in positive activities, like doing sports, instead of being delinquent, or might choose better friends, who provide emotional or school-related support. Positive health behavior, participation in beneficial leisure time activities, and higher levels of social support, in turn, are associated with higher levels of life satisfaction (e.g. $\mathrm{Hu} \& \mathrm{Mu}, 2020$; Moore et al., 2018; Proctor et al., 2009). Finally, higher levels of skills and knowledge increase the individual's life satisfaction levels by satisfying one of the three innate psychological needs, namely the need for competence. Next to the need for relatedness and the need for autonomy, feeling competent is assumed essential for an individual's psychological well-being. It is assumed that higher levels of skills and knowledge increase children's life satisfaction as they reinforce their feelings of competence by experiencing high effectiveness in mastering daily challenges and given tasks (Ryan \& Deci, 2000).

Therefore, I derive my first hypothesis:

\section{H1: The higher the children's levels of academic competencies, the higher their life satisfaction.}

Regarding the effect of children's school grades, however, psychological approaches highlight the importance of positive or negative evaluations of children's performance in and outside school. During childhood, individuals create their self-image based on the feedback of others and opinions about themselves in daily life. Thus, independently of the true level of skills and knowledge, children develop perceptions of their (in-)competence depending on the feedback received. Next to feedback from parents and peers, especially the feedback from teachers in terms of school grades is expected to play a central role. Therefore, positive evaluations in 
the form of higher grades are assumed to increase children's perceptions of competence and should increase children's levels of self-esteem, self-perceived efficacy, and future optimism, which are closely linked to higher levels of life satisfaction. In contrast, negative feedback in terms of low school grades should result in lower levels of life satisfaction, because children attribute the negative evaluations to their skills and knowledge, develop a feeling of incompetence, and have lower levels of self-esteem, self-perceived efficacy, and future optimism (Cole et al., 2001; Dweck \& Leggett, 1988; Eicher et al., 2014; Herman et al., 2008). Based on these theoretical arguments, I derive my second hypothesis:

\section{H2: The better the children's school grades, the higher their life satisfaction.}

These hypotheses refer to the unconditioned versions, i.e. the total causal effect of either academic competencies or school grades without controlling for the other. However, other theoretical expectations can be derived for the case when both competencies and grades enter the model simultaneously. In line with the skill-related arguments, the effect of school grades should diminish if academic competence levels are taken into account because they represent direct measures of the unobserved skills. However, since school grades represent more than just differences in skills and knowledge, they may also be of further relevance to children's life assessment, because they refer to positive or negative evaluations of children's performance. Thus, complementing the human-capital approach self-determination theory assumes, that, despite children's actual levels of academic competence, children with lower grade levels should report lower levels of life satisfaction, because getting bad grades might be a signal for failure in a specific task. This results in lower selfesteem, less positive perceptions about one's future, and negative self-evaluations, which might decrease student's life satisfaction (Herman et al., 2008). In contrast, earning higher grades reflect higher goal achievement in school and should lead to stronger beliefs of being competent, higher self-esteem, and higher feelings of selfefficacy, all leading to more positive life evaluations. Therefore, even when competencies are controlled, school grades should positively affect children's life satisfaction. Moreover, school grades might partly explain the effect of children's academic competence levels on their life satisfaction as they refer to the psychological mechanisms. Thus, controlling for grades in the effect of competencies on life satisfaction should result in the estimation of the direct effect of skills on life satisfaction.

This leads to two more hypotheses:

H3: It is expected that the conditional effect of children's levels of academic competencies is lower than the unconditional effect because the effect is partly explained by children's school grades.

H4: The effect of school grades should be smaller in the conditional model compared to the unconditional one because competence levels act as a confounder.

While the theoretical arguments provided so far postulate positive effects of children's competence levels and school grades on life satisfaction, there also exist theoretical counter-arguments as well as implications for a reverse causal link. On the 
one hand, high levels of competencies and school grades might result in lower levels of life satisfaction if the need for relatedness is not met (Ryan \& Deci, 2000). Perceived social exclusion due to rejection or victimization by peers based on high levels of competence and school grades might decrease children's life satisfaction, because, depending on the educational context, extremely high levels of competencies and grades might lead to lower levels of social connectedness. Especially in contexts with lower average levels of skills and knowledge, high-achieving children might have higher difficulties because peers with average skill levels tend to react to the threat of feeling less competent. For instance, they tend to be aggressive or harassing in social interactions with high-achieving children, which. Might result in lower life satisfaction levels of the affected child (Arslan, 2018). On the other hand, life satisfaction might also enhance children's levels of competencies and school grades, because higher life satisfaction is assumed to increase positive emotions which affect cognitive function and personal resources for learning and acquiring knowledge (Fredrickson, 2004). Therefore, being satisfied with life and having a high value of subjective well-being may enhance individuals' academic achievement (Pekrun et al., 2006; Valiente et al., 2012).

However, even though theoretical arguments suggest negative consequences of children's competence levels and school grades as well as a reverse relationship, these counter-arguments should not negate the previous argumentation. As exemplarily shown by Bergold et al. (2020), higher competence levels prevent children from being bullied in school. Results indicate, that the higher the children's competence levels the lower the prevalence of bullying (Bergold et al., 2020). Therefore, children with higher levels of competence should be less likely to feel socially excluded and diverging effects should not contradict prior arguments. Moreover, as pointed out by $\mathrm{Ng}$ et al. (2015), the effect of life satisfaction on school grades seems to be less important compared to the influence of school grades on satisfaction. Thus, even if the effects of children's competence levels and school grades on life satisfaction could be opposite and children's life satisfaction influences their levels of competencies and school grades, the effects postulated in hypotheses one to four should be the dominant ones.

\subsection{Heterogeneous Effects of Children's Competencies and School Grades by Secondary School Track}

Despite the aforementioned theoretical arguments and the suggested link between children's competence levels, grades, and life satisfaction, it is questionable if the relationship shows up to be similar for all children. As empirical literature suggests, there might be differences between subgroups by several individual-specific or context-related characteristics. Studies indicate differences in the relationship between competencies and school grades and life satisfaction by gender, age, culture, and educational setting (e.g. Chang et al., 2016; Nordlander \& Stensöta, 2014; Suldo et al., 2016).

As one important factor of educational settings, school tracks might be of relevance for the effect of children's academic competencies and school grades on 
life satisfaction. For example, in Germany, the case studied, after primary schooling starting in the age around 6 tracking into lower, intermediate and higher secondary schools occurs at about age ten and this then defines different pathways to further education and training (for detailed information see Fig. 1 in Appendix and Kultusministerkonferenz (2019). While lower and intermediate secondary schools prepare for vocational apprenticeship training, the higher secondary school track aims to prepare children for tertiary education. Thus, children in different school tracks face different opportunities and constraints for their future. While children in the higher secondary school track face positive prospects in getting a position in vocational training or going on with tertiary education, children in lower and intermediate school tracks are limited to vocational education and face several challenges in getting an apprenticeship. In addition, attending the lowest educational school track does not only affect the number of options for further education and training, it decreases the children's probability of getting a vocational training position tremendously (e.g. Fitzenberger et al., 2015).

These differences in prospects might result in differences in the relevance of school-related feelings of competence for children's life evaluation. It is assumed that, during secondary schooling, children tend to adapt to their perceptions of the future and if necessary compensate for need frustration with alternative strategies. Especially children in the lowest educational school track, who have the lowest level of future opportunities, tend to react to their less prospective future (Eccles \& Roeser, 2011). Thus, they are more likely to show maladjustments in terms of ill-being, develop different behavioral patterns stabilizing their selfworth, like heavy gaming, or react to it by oppositional defiance in form of deviant behavior and action against authorities (Vansteenkiste et al., 2020). These adaption processes result in higher relevance of other life domains and therefore shape how children evaluate overall life satisfaction. For instance, these children might be more likely to evaluate their lives in terms of sports, peer relationships, family, and standards of living. In contrast, children in higher secondary schools experience a higher value of school-related feelings of competence based on valuable future opportunities. The possibility of reaching a high level of education could lead to a stronger focus on high levels of school performance because performing well increases their chances to reach the goal. Thus, they pay more attention to school-related feedback and, consequently, children in the higher track should be more affected by a negative response. Since they face a higher risk of losing chances of reaching a higher level of education or prestigious job positions, school-related aspects might be highly important for their life satisfaction.

Therefore, it might well be argued, that the effect of school grades on life satisfaction might be stronger for children in higher secondary school tracks compared to children attending the lower school track. Children in the higher track should be more affected by school grades because they reflect the evaluations of schoolrelated competence levels by teachers and indicate success or failure in terms of school-related tasks. Thus, getting poor school grades might indicate a failure in a specific task, which is accompanied by a higher risk of losing chances of reaching the next level. In contrast, the level of life satisfaction of children in the lowest 
school track might not vary by school grades, because school-related aspects are not highly relevant in their life evaluations.

However, the link between children's competence levels and life satisfaction might not be moderated by the school track, because the differences between school tracks mainly account for variation in the importance of school-related feelings of competence. Despite that, having higher levels of competence should steadily lead to higher life satisfaction by increasing children's and youth skills in problem-solving and mastering challenges. Irrespectively of the school track attended, children with higher competence levels should have higher levels of coping strategies, manage (school-related) tasks more easily and invest more in positive means to enhance their overall life satisfaction. Therefore, a moderation effect of the school track attended should only be observable for school grades not for children's competence levels.

In line with these arguments, I derive two additional hypotheses:

H5a: The positive effect of children's competencies on overall life satisfaction does not differ between lower, middle, or higher secondary school tracks

$H 5 b$ : The relationship between children's and youth school grades is weaker in lower secondary school tracks compared to middle and higher secondary school tracks.

\section{Method}

\subsection{Data}

This study uses data of starting cohort 3 (5th graders) of the NEPS in Germany, which is the first to allow for longitudinal analysis of the effect of competence levels and school grades on life satisfaction in children based on representative data in Germany (Blossfeld \& Roßbach, 2019). The sample of starting cohort 3 consists of representatively selected 5th-grade students in secondary school tracks in regular as well as special schools. The sample is stratified in class-school levels in the federal states in Germany and contains three subsamples, the main sample including children randomly selected from classes, a migrant supplement including only children with a migrant background, and a refreshment sample in wave 3 (Steinhauer \& Zinn, 2016). The annual survey was first conducted in 2010 and paper-based questionnaires and competence tests were administered in classes in schools during one or two school days. However, if a student left school or the school refused further cooperation with the survey institute, questionnaires were sent home. Context information about the school and class level as well as competencies are no longer available for this group.

For the present study, I have used data of grades five, seven, and nine including waves one, three, five, and six, because competencies in reading and mathematics are only available in these respective years. I have only used data of the main sample because the sampling procedure and measurements of children's competence levels differed slightly between the migrant supplement and the main part of the sample 
(Steinhauer \& Zinn, 2016). I have restricted the sample to children who attended at least two waves and use only individuals, who were surveyed in the school context in regular schools. Moreover, I restrict the sample to individuals, which attended the same school during the observation period to ensure a comparable sample structure over time. Finally, I have only included children without missing values in relevant variables, which resulted in 2602 dropped observations and 488 missed complete cases in total. In the end, the sample consists of 3045 individuals nested in 155 schools and 356 classes in a maximum of three waves. Each individual was observed about 2.3 times on average. The mean age is about 12 years and ranges from 10 to 15 between waves. About $7 \%$ of the sample attended the lower secondary school track, while about $29 \%$ and $65 \%$ attended the middle secondary or higher secondary school track, respectively. Children in the lower secondary school track participated in about 2 waves on average, while children in middle and higher secondary schools participated in about 2.3 and 2.5 waves, respectively.

\subsection{Statistical Analyses}

To test the theoretically-driven hypotheses, I have used fixed effects panel regression models, which are based on the following basic linear regression model:

$$
y_{i t}=X_{i t} \beta+\alpha_{i}+\varepsilon_{i t}
$$

In general, this models refer to a linear relationship between a dependent variable $\left(y_{i t}\right)$ and two or more independent variables $\left(X_{i t} \beta\right)$ repeatedly measured in subjects $(i)$ and time $(t)$. They have two error components, one representing time-constant subject-specific characteristics $\left(\alpha_{i}\right)$ and an idiosyncratic error term $\left(\varepsilon_{i t}\right)$, which refers to time-varying subject-specific characteristics. By demeaning the variance of subject-specific means, fixed effects panel regression models use the within variation within subjects over time only to predict the effect of changes in $X_{i t} \beta$ on the respective outcome variable $(y)$. This eliminates time-constant subject-specific variation as represented in $\alpha_{i}$. Thus, estimates are not biased by time-constant subjectspecific confounding factors, like intelligence, family background characteristics, or genes (Brüderl \& Ludwig, 2014). However, a bias may occur in case of time-varying cofounding variables.

Following the basic idea, for this study the overall regression model is as follows:

$$
\text { satis }_{i t}=\beta_{0 t}+\beta_{1} \text { competencies }_{i t}+\beta_{2} \text { school grades }_{i t}+\gamma_{1} \text { controls }+\alpha_{i}+\varepsilon_{i t}
$$

Here, satis $_{i t}$ denotes children's $(i)$ overall life satisfaction reported on time $t$ and will be explained by children's competencies $_{i t}$ and school grades $_{i t}$. Observed timevarying confounding variables are included as control variables. $\alpha_{i}$ reflects the timeconstant error term including time-constant characteristics, like children's gender, migration background, socio-economic background, personality traits, intelligence, and school context variables. In turn, $\varepsilon_{i t}$ represents the unobserved time-varying individual characteristics.

The estimation procedure follows a stepwise approach. In the first step, to test hypotheses one and two, the effects of children's competencies (Model 1a) and 
school grades (Model 2a) will be estimated separately. In a second step, to test hypotheses three and four, both indicators will be included in one model (Model 3a). In a third step, following the same procedure from step one and two, interaction effects by school track are included to test the theoretical expectations about heterogeneous effects of the school track attended (Model $1 \mathrm{~b}$ to Model 3b). Finally, I conduct a sensitivity analysis for the main effect of children's competence levels and school grades on their life satsifaction by investigating differences in the relationship by gender, since prior literature suggest variation between girls and boys (e.g. Pomerantz et al., 2002; Nordlander \& Stensöta, 2014).

\subsection{Variables}

Life Satisfaction Children's life satisfaction refers to their overall evaluation of life in terms of goals achievement and subjective criteria in all subjectively important life domains and relates to the cognitive well-being of children (Diener et al., 2009; Diener, 1984; Huebner, 2004). It is linked to individuals' life circumstances, indicates long-term average mood and longstanding consequences of life events (e.g. Diener et al., 2013; Suldo et al., 2016), and is strongly associated with children's mental health (e.g. Fergusson et al., 2015; Gilman \& Huebner, 2003). Higher levels of life satisfaction arise if goals are reached and subjective standards in life are fulfilled (Diener, 1984). To measure life satisfaction, I use a single-item question asking "How satisfied are you currently and in general terms with your life?", which is well established in well-being research and shows high reliability compared to multi-item scales, even for youth (Cheung \& Lucas, 2014; Frey \& Stutzer, 2002; Jovanović, 2016; Kahneman \& Krueger, 2006). The scale ranges from 0"completely dissatisfied" to 11 "completely satisfied". For later analysis, the measurement is included as a metric variable. On average, children reported a high level of life satisfaction. I observe a mean level of overall satisfaction of about 8 scale points (see Table 1).

School Grades To measure the children's school grades, I used the combined mean of students' self-reports of final grade point averages in Math and German of the previous school year ranging from 1 "very good" to 6 "unsatisfactory". Selfreported GPA in German and Math are highly correlated with actual school grades and should be a good substitute for actual GPA (Sticca et al., 2017). Although, validation studies indicate, that self-reported school grades are somewhat biased by children's actual school performance levels (Credé \& Kuncel, 2013; Kuncel et al., 2005), estimating the effect of school grades on life satisfaction should not be limited by these differences. Since the panel regression model only uses intra-individual variation for predicting the effect of school-grades on life satisfaction time-constant variation between individuals should not bias estimation results. In line with previous research and for easier interpretation, I inverted the scale so that it now ranges from 1" unsatisfactory" to 6" very good". Children's school grades range from 1 to 6 and are about 4.6 for German and about 4.5 for Math. Differences between individuals are about 0.7 and 0.8 , respectively (see Table 1 ). 
Table 1 Descriptive statistics of main variables $(N=7085 ; n=3045)$

\begin{tabular}{|c|c|c|c|c|c|}
\hline Variable & - & Mean & Std. Dev. & Min & Max \\
\hline \multirow[t]{3}{*}{ Life satisfaction } & overall & 7.90 & 2.15 & 0 & 10 \\
\hline & between & & 1.73 & 0 & 10 \\
\hline & within & - & 1.40 & 1.23 & 14.57 \\
\hline \multirow[t]{3}{*}{ School grade (German) } & overall & 4.56 & 0.84 & 1 & 6 \\
\hline & between & & 0.72 & 2 & 6 \\
\hline & within & - & 0.49 & 2.23 & 6.89 \\
\hline \multirow[t]{3}{*}{ School grade (math) } & overall & 4.53 & 0.96 & 1 & 6 \\
\hline & between & & 0.79 & 1 & 6 \\
\hline & within & - & 0.58 & 2.20 & 7.20 \\
\hline \multirow[t]{4}{*}{ School grade (mean) } & overall & 4.55 & 0.78 & 1 & 6 \\
\hline & between & & 0.66 & 1.50 & 6 \\
\hline & within & - & 0.46 & 2.21 & 7.05 \\
\hline & overall & 0.91 & 1.30 & -3.41 & 6.24 \\
\hline \multirow[t]{3}{*}{ Reading competence } & between & & 1.12 & -3.09 & 5.18 \\
\hline & within & - & 0.73 & -2.59 & 4.26 \\
\hline & overall & 1.05 & 1.29 & -4.57 & 6.82 \\
\hline \multirow[t]{3}{*}{ Mathematical competence } & between & & 1.12 & -3.68 & 4.57 \\
\hline & within & - & 0.73 & -2.68 & 4.48 \\
\hline & overall & 12.33 & 1.63 & 8 & 16 \\
\hline \multirow[t]{3}{*}{ Age } & between & & 0.98 & 9 & 16 \\
\hline & within & & 1.40 & 9.66 & 14.99 \\
\hline & overall & 1.73 & 0.76 & 1 & 5 \\
\hline \multirow[t]{2}{*}{ Subjective health status } & between & & 0.63 & 1 & 4.50 \\
\hline & within & & 0.46 & -0.27 & 4.40 \\
\hline
\end{tabular}

Source: NEPS SUF SC3 9.0.0 (download); doi:https://doi.org/10.5157/NEPS:SC3:9.0.0; own calculation

Academic Competencies To measure children's academic competencies, I used results of competence tests administered in the domains of reading and math conducted in NEPS, which both represent multidimensional skills of individuals related to these domains (for more details see Weinert et al., 2011). Both tests include a maximum of 33 items and last approximately $30 \mathrm{~min}$. Test results are scaled as

Table 2 Classification of school tracks based on school type attended

\begin{tabular}{ll}
\hline Lower secondary & Hauptschule \\
& Comprehensive school - lower secondary level \\
& School with several course levels - lower secondary level \\
Middle secondary & Realschule \\
& Comprehensive school - middle secondary level \\
& School with several course levels - middle secondary level \\
Higher secondary & Gymnasium \\
& Comprehensive school - higher secondary level \\
& School with several course levels - higher secondary level \\
\hline
\end{tabular}

Source: Own illustration 
conditional probabilities for achieving a specific ability level based on Rasch-models and linked by mean-to-mean based on anchor items across waves (Fischer et al., 2016). To analyze the relationship between children's competencies and life satisfaction, I used uncorrected weighted maximum likelihood estimates as recommended by van de Ham et al. (2018) and Scharl et al. (2017). I included the metric scores ranging from -4.39 to 6.82 . Sample specific descriptive statistics are presented in Table 1. Children in starting cohort 3 showed lower levels in reading compared to math. While the mean level in reading is about 0.9 , the level in math is about $1.1{ }^{1}$

School Track Attended To identify the school track attended I used information about the type of school offered in NEPS. I assigned children to the respective secondary school track if they either reported that they attend the respective school type, or the respective level in a comprehensive school or a school with several course levels (see Table 2).

Confounding Factors and Control Variables As discussed in the literature the relationship between educational achievement and life satisfaction might be confounded by several individual and background-related variables. However, since fixed effects regression models already eliminate time-constant confounding variables, I only focused on time-varying components, which are assumed to affect educational achievement and life satisfaction as well as are not already considered by the sample definition and the statistical approach. I control for children's age, age-wave effects, class-level characteristics, and children's health status. Children's age was included as a metric variable measuring children's age at the time of the interview and class-level characteristics were controlled by considering class-level fixed effects. Children's health status was measured by the question "How would you generally describe your state of health?" with a scale ranging from one ("very good') to five ('very bad'). ${ }^{2}$ Next to these included controls, life events, such as changes in residence, school, or family structure and parental job loss which require high levels of coping and adaption, might also affect children's educational achievement and life evaluation (e.g. Carlson \& Corcoran, 2001; Mostafa et al., 2018; Pribesh \& Downey, 1999; Proctor et al., 2009). However, due to the restriction of the sample only to children without any school change, I observed no changes in residence and school. Moreover, I observed only a very small variation in family structure between panel

\footnotetext{
1 I estimated additional panel models to check the correlations between individuals' academic competencies and school grades. Results show, that academic competencies and school grades are only moderately correlated. Lower levels in academic competencies are associated with lower grade point averages. However, explained variation for differences between individuals is about $40 \%$ for GPA in German and $30 \%$ for GPA in Math. About 30\% of the variation of school grades are explained by changes in academic competence levels within individuals (detailed information are available upon request).

2 Although objective measurements of children's health status are largely preferred because subjective health status may be biased due to social and psychological factors that influence children's self-monitoring, the NEPS study only provides sufficient information on children's health based on their own subjective ratings.
} 
Table 3 Results of fixed-effects panel regression of the effect of children's competencies and school grades on life satisfaction

\begin{tabular}{llll}
\hline & Modell 1a & Modell 2a & Modell 3a \\
\hline Reading competence & $0.072 *$ & & 0.068 \\
& $(0.0426)$ & & $(0.0426)$ \\
Mathematical competence & -0.016 & & -0.028 \\
& $(0.0513)$ & & $(0.0507)$ \\
School grade (mean) & & $0.246 * * *$ & $0.244 * * *$ \\
& & $(0.0631)$ & $(0.0632)$ \\
Constant & $10.775 * * *$ & $12.577 * * *$ & $10.838 * *$ \\
& $(1.1001)$ & $(1.0239)$ & $(1.0972)$ \\
Within-R & & 0.1352 & 0.1360 \\
Observations & 0.1318 & 7085 & 7085 \\
N & 7085 & 3045 & 3045 \\
\hline
\end{tabular}

Source: NEPS SUF SC3 9.0.0 (download); doi:https://doi.org/10. 5157/NEPS:SC3:9.0.0

${ }^{*} p<0.10,{ }^{* *} p<0.05,{ }^{* * *} p<0.01$; clustered standard errors by school level in parentheses; controls: age; age-wave effects; class fixed effects; subjective health status

waves. Thus, residential-, school-and family-related characteristics can be assumed to be time-constant and will be eliminated by the time-constant error term.

\section{Results}

Results of fixed effects regression analyses are presented in Tables 3 and 4. Table 3 shows the results of the estimation of the effect of both measurements of educational achievement on life satisfaction without considering differences by attended school track. The first and the second model show results of predicted life satisfaction on competencies and school grades separately. The third model includes both. For all models, the within- $\mathrm{R}^{2}$ indicates that the model explains about $13 \%$ of the variation in life satisfaction of each individual. For children's competence levels, Model 1a indicates that neither reading nor math competence levels affect children's life satisfaction. Both coefficients are very small and not statistically significantly different from zero. This contradicts hypothesis 1, where a positive effect of children's competencies on life satisfaction was expected. Regarding the effect of children's school grades, Model 2a predicts that an increase by one grade increases children's life satisfaction by about 0.24 scale points, which is in line with the second hypothesis. Model 3a substantiates these results. Children's competence levels seem to be unrelated to their life satisfaction and controlling for school grades, results do not differ between Model 3a and Model 1a. Furthermore, Model 3a shows that school grades are already important for children's life satisfaction even when competencies are controlled. However, contradictory to hypothesis 4, controlling for children's 
Table 4 Results of fixed effects regressions including heterogeneous effects by school track

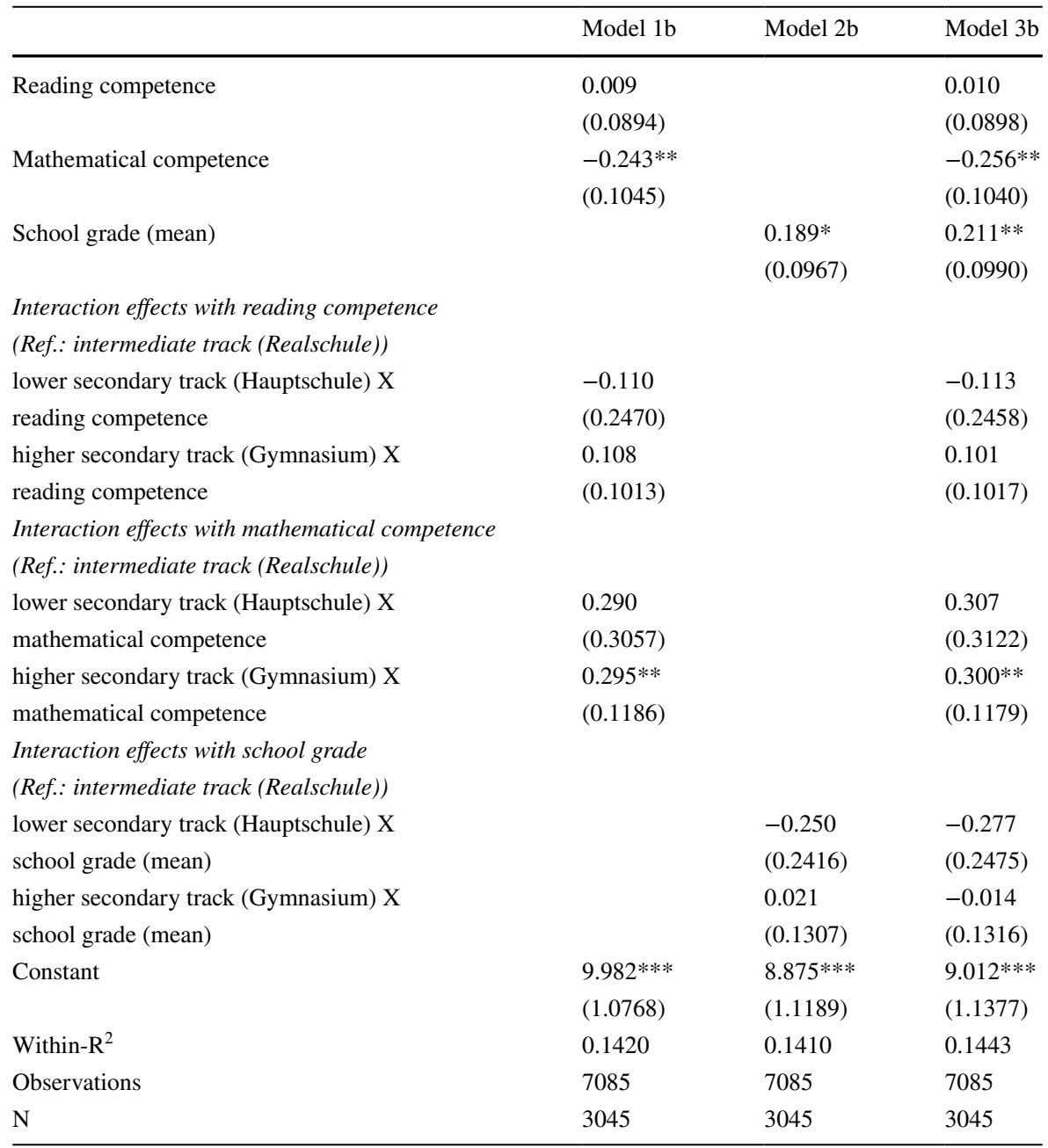

Source: NEPS SUF SC3 9.0.0 (download); doi:https://doi.org/10.5157/NEPS:SC3:9.0.0

${ }^{*} p<0.10,{ }^{* *} p<0.05,{ }^{* * *} \mathrm{p}<0.01$; clustered standard errors by school level in parentheses; controls: age; age-wave effects; class fixed effects; subjective health status

competence levels does not decrease the estimated effect of children's school grades on their life satisfaction.

Regarding hypotheses $5 \mathrm{a}$ and $5 \mathrm{~b}$, Table 4 shows the results by taking the interaction effects with the school track attended into account. Compared to models 1a to 3a, the main effects of children's grades and competencies now represent the effect of both on life satisfaction only for children in middle secondary school track as they are defined as the reference category in the interactions. Model 1b shows the results of the predicted life satisfaction based on children's competencies. Similar to the main model, children's reading competence seems to not affect their life satisfaction; 
the coefficient is very close to cero. Nevertheless, considering differences in school tracks change results regarding the impact of mathematical competence on children's life satisfaction. The main effect becomes significantly different from zero and negative, which indicates that children attending the middle secondary school track report lower life satisfaction levels if they achieve higher levels in mathematical competence. This seems to be also true for children in lower secondary schools because observed differences are not significant for this group. In contrast, for children in higher secondary schools, mathematical competence levels appear to be positively related to children's life evaluations, and differences compared to children in middle secondary schools are significant. Model 3b confirm these results, which, however, contradict Hypothesis 5a, because they highlight variation in the effect of children's competence levels on life satisfaction.

Referring to hypotheses 5b, Model $2 \mathrm{~b}$ and Model $3 \mathrm{~b}$ indicate that school grades are still important for children's life evaluations in middle secondary schools and there are no significant differences between school tracks. Although coefficients of the interaction terms indicate that the effect of school grades on the life satisfaction of children who attend the lowest secondary school track is lower than for children in middle and higher secondary schools, these differences are not significant. Moreover, results highlight, that children in higher secondary school track do not differ substantially from children in middle secondary schools since the interaction effect is very close to zero. Therefore, even though the coefficients point in the expected directions, results contradict theoretical assumptions, since these differences are not significant.

However, to see whether differences between boys and grils drive the main results presented in Table 3, I tested for further heterogeneity by considering variation by gender in an additional senstivity check. Results of the sensitivity analyses are presented in Table 5. Fixed-effects regression models underline the positive relationship between children's school grades and reported life satisfaction. As depicted in Model $2 \mathrm{c}$ and $3 \mathrm{c}$ the effect of school grades remains stable and the interaction term with gender does not suggest differences between girls and boys. However, for the effect of children's academic competencies results suggest differences between girls and boys. While results in the main part do not show differences in children's life satisfaction by academic competence levels, considering differences by gender suggest that higher mathematical competence levels are associated with lower life satisfaction for boys. Thus, it seems that mathematical competencies are associated with gender-specific experiences affecting girls and boys levels of life satisfaction differently. ${ }^{3}$ Therefore, to sum up, sensitivity analyses support hypothesis 1 for girls, but not for boys and suggest that higher competence levels in mathematics are associated with lower life satisfaction levels for the latter. However, they are in line with hypothesis 2 and suggest a positive relationship between school grades and life satisfaction for both boys and girls.

\footnotetext{
3 The same conclusion remains when gender differences are included in separate regression models instead of interaction effects.
} 
Table 5 Results of fixed effects regressions including heterogeneous effects by gender

\begin{tabular}{|c|c|c|c|}
\hline & Modell 1c & Modell 2c & Modell 3c \\
\hline Reading competence & $\begin{array}{l}0.044 \\
(0.0556)\end{array}$ & & $\begin{array}{l}0.043 \\
(0.0558)\end{array}$ \\
\hline Mathematical competence & $\begin{array}{l}-0.205 * * * \\
(0.0689)\end{array}$ & & $\begin{array}{l}-0.212 * * * \\
(0.0691)\end{array}$ \\
\hline school grade (mean) & & $\begin{array}{l}0.283 * * * \\
(0.0939)\end{array}$ & $\begin{array}{l}0.290 * * * \\
(0.0943)\end{array}$ \\
\hline \multicolumn{4}{|c|}{$\begin{array}{l}\text { Interaction effects with reading competence } \\
\text { (Ref.: boys) }\end{array}$} \\
\hline girls $\mathrm{X}$ reading competence & $\begin{array}{l}0.090 \\
(0.0821)\end{array}$ & & $\begin{array}{l}0.086 \\
(0.0820)\end{array}$ \\
\hline \multicolumn{4}{|c|}{$\begin{array}{l}\text { Interaction effects with mathematical competence } \\
\text { (Ref.: boys) }\end{array}$} \\
\hline girls X mathematical competence & $\begin{array}{l}0.380 * * * \\
(0.1062)\end{array}$ & & $\begin{array}{l}0.375 * * * \\
(0.1075)\end{array}$ \\
\hline \multicolumn{4}{|l|}{$\begin{array}{l}\text { Interaction effects with school grade } \\
\text { (Ref.: boys) }\end{array}$} \\
\hline girls X school grade (mean) & & $\begin{array}{l}-0.078 \\
(0.1261)\end{array}$ & $\begin{array}{l}-0.117 \\
(0.1244)\end{array}$ \\
\hline Constant & $\begin{array}{l}9.802 * * * \\
(1.1389)\end{array}$ & $\begin{array}{l}8.581 * * * \\
(1.1916)\end{array}$ & $\begin{array}{l}8.513 * * * \\
(1.1756)\end{array}$ \\
\hline Within- $\mathrm{R}^{2}$ & 0.1564 & 0.1550 & 0.1604 \\
\hline Observations & 7085 & 7085 & 7085 \\
\hline $\mathrm{N}$ & 3045 & 3045 & 3045 \\
\hline
\end{tabular}

Source: NEPS SUF SC3 9.0.0 (download); doi:https://doi.org/10.5157/NEPS:SC3:9.0.0

${ }^{*} p<0.10,{ }^{* *} p<0.05,{ }^{* * *} p<0.01$; clustered standard errors by school level in parentheses; controls: age; age-wave effects; class fixed effects; subjective health status

\section{Discussion and Conclusion}

The present study aimed was to examine the effect of children's competence levels and school grades on life satisfaction in secondary schools. Empirical results contribute to previous literature by addressing methodological shortcomings of prior research, like a scarce number of longitudinal analyses, omitted variable bias, and limitations in causal inference. Moreover, this paper provided insights into differences in the importance of children's academic competencies and school grades for their life satisfaction and investigated heterogeneous effects by attended school track. Drawing on information from waves one, three, four, and five of a sample of 3045 secondary school students of the National Educational Panel Study in Germany (NEPS) results suggest, that it is mainly children's school grades which contribute to their life satisfaction. In line with previous studies and supporting theoretical expectations based on self-determination theory, school grades seem to be positively linked to children's 
life evaluations (e.g. Edgar et al., 2015; González et al., 2020; Ng et al., 2015; Reysen et al., 2017). Similar to studies in other countries, for example, the United States (e.g. Lyons \& Huebner, 2016; Reysen et al., 2017) or Chile (e.g. González et al., 2020), with comparable operationalizations of the two variables, the effect sizes suggest a small to moderately strong impact of school grades on life satisfaction, regardless of the school track attended. This suggests that, for all children, positive evaluations of school-related performance are important for their life satisfaction.

However, children's levels of academic competencies are only partly related to their life evaluations. While predicted estimates show, that higher competence levels in math decrease children's life satisfaction levels in lower and middle secondary schools and increase children's life satisfaction in higher secondary schools, competence levels in reading seem to be unrelated to children's life evaluations. These results contradict some prior studies (e.g. Chen \& Lu, 2009; Lyons \& Huebner, 2016; Martin et al., 2014), which might highlight the importance of confounding bias in previous studies. For example, earlier findings suggesting a positive relationship between competencies and children's well-being are not controlled for individual and family-related background characteristics, such as intelligence and socioeconomic background (e.g. Chen \& Lu, 2009; Lyons \& Huebner, 2016). Additionally, differences compared to prior studies might highlight the importance of the individual's characteristics moderating the relationship. As previous results are often based on samples including older children in secondary school tracks, high schools, or in tertiary education, they indicate differences in the relationship between children's academic competencies and life satisfaction by educational setting and age (e.g. Chen \& Lu, 2009; Felsten \& Wilcox, 1992; Flett et al., 2009). Thus, compared to prior studies, the present study shows some advantages, since unobserved heterogeneity in time-constant individual characteristics is eliminated by fixed effects panel regressions and differences between school tracks are examined for children of the same age. Though, also fixed effect regression estimates can still be biased if there are unobserved time-varying confounding variables.

Differences in the effect of children's academic competence levels on their life satisfaction by school track also contradict theoretical arguments. As established by human capital theory, higher competence levels are expected to have a positive effect on life satisfaction levels for all children. Thus, especially, the negative relationship between mathematical competencies and life satisfaction for children in lower and middle secondary schools seem to be counterintuitive. However, these results might highlight the consequences of the relationship of high achievement in school and underload in schoolwork for school-related boredom and frustration. As research in high achieving children suggests, the higher capabilities within a context of lower requirements, the higher the probability of being bored and frustrated in the specific context (Feldhusen \& Kroll, 1991; Jin \& Moon, 2016; Larson \& Richards, 1991). This might result in lower life satisfaction, especially if children feel mismatched in their current school track. Thus, the negative effect of mathematical competencies in children attending the lower secondary school tracks might indicate that especially highly competent children in these schools suffer from underload in school-related work and frustration. This point out some consequences of wrong track placement in secondary schools. 
In addition to these differences in the effect of children's academic competence levels on their life satisfaction, taking into account the school track attended, sensitivity analyses also show differences between boys and girls. While higher mathematical competencies are negatively associated with life satisfaction for boys, the effect is the opposite for girls. This could indicate gender-related consequences of higher achievement in children's everyday experiences, as high levels of mathematical competencies are assumed to have a different meaning for boys and girls. It is hypothesized, that higher levels of competence represent higher levels of school engagement, which is more likely to be associated with typical female gender roles. Thus, higher mathematical competence levels for boys might reflect low gender typicality, which could negatively affect their peer relations in school. For example, Bergold et al. (2020) emphasize that high-achieving boys have a higher risk of being bullied at school, which could explain the negative effect on their life satisfaction.

Although the present study shows some new and interesting insights into the relationship between children's academic competencies, school grades, and life satisfaction, there are some limitations left to be considered. First, the sample consists only of students without any school change. This might result in a selective sample structure containing individuals, who are more likely to have stable family environments, continuous educational careers, and no residential moves during the observation period. Second, the sample was restricted to students participating in at least two panel waves, which might lead to additional selectivity in the students' sample. For example, students in lower and higher secondary schools are more likely to drop out of the panel than students in middle secondary school track are. Furthermore, students with higher grades in German, lower grades in math, students from the younger half of the sample, and females are more likely to participate in the survey (Steinhauer \& Zinn, 2016). Thus, the sample becomes more homogeneous regarding children's competence levels, school grades, and age. This selectivity might affect the results, because of the smaller variance in the respective variables. In this case, the results presented above would be lower-bound estimates and, likely, the effects of children's academic competencies and school grades on life satisfaction are underestimated (Winship \& Mare, 1992). Third, the operationalization of children's life satisfaction by only asking one single question raises concerns about the validity and reliability of the measurement, which cannot be directly addressed with NEPS data. It might be possible, that compared to a multi-item measurement the global indicator is less sensitive for changes over time and differences in life satisfaction between children. This would lead to a further reduction of the effect of children's academic competencies and school grades on life satisfaction. Finally, fixed effect regression estimates can still be biased if there are unobserved time-varying confounding variables. For example, NEPS data do not provide detailed information about parent's employment trajectories, which may both affect children's competence levels, school grades, and life satisfaction.

Notwithstanding these limitations, the study provides deeper insights into the effect of children's competence levels and school grades on their life satisfaction and contributes to the discussion about a causal relationship. Even though the effects of academic competencies and school grades on life satisfaction are possibly underestimated, the study highlights the importance of school grades. The study also points 
out inequalities between school tracks and gives some hints about the effects of tracking in Germany. Moreover, sensitivity analyses show some differences between boys and girls, which raise the question about the relevance of further mechanisms linking children's academic competence levels to life satisfaction. Thus, further research should replicate these results by using another longitudinal dataset, address underlying mechanisms and make further differences in subgroups to help politicians and professionals in the educational system avoid the long-term consequences of low life- satisfaction early in life such as later life depressive symptoms or anxiety disorders. For example, as suggested by Ocal and Altınok (2016) or Suldo et al. (2013) enhancing service-learning projects which address children's feelings of competence, student-teacher relationship and parental involvement in school might be a potential strategy.

\section{Appendix}

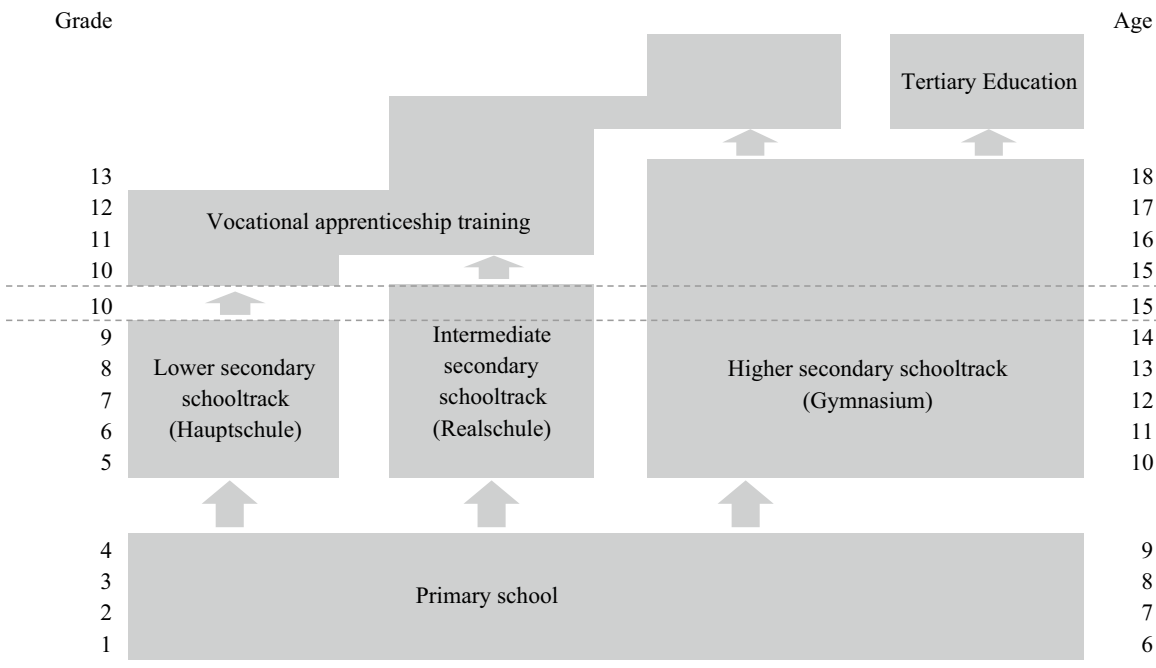

Fig. 1 German education system. Source: Kultusministerkonferenz (2019), own adaptation

Acknowledgements The author thanks Michael Gebel and colleagues from the Leibniz Institute of Educational Trajectories and the Chair for Economics, esp. Empirical Microeconomics of the University of Bamberg for helpful discussions and comments. I also thank the participants of the Online-Workshop "Causality in the Social Sciences II" 2020 sponsored by the Akademie für Soziologie. This paper uses data from the National Educational Panel Study (NEPS): Starting Cohort 3 - 5th Grade, https://doi.org/ 10.5157/NEPS:SC3:8.0.1. From 2008 to 2013, NEPS data were collected as part of the Framework Programme for the Promotion of Empirical Educational Research funded by the German Federal Ministry of Education and Research (BMBF). As of 2014, the NEPS survey is carried out by the Leibniz Institute for Educational Trajectories (LIfBi) at the University of Bamberg in cooperation with a nationwide network. 
Authors' Contributions Not Applicable.

Funding Open Access funding enabled and organized by Projekt DEAL.

Data Availability Not applicable.

Code Availability Codes on data preparation and conducted analyses are available upon request.

\section{Declarations}

Conflicts of Interest/Competing Interests The author declares that there is no conflict of interest to declare.

Open Access This article is licensed under a Creative Commons Attribution 4.0 International License, which permits use, sharing, adaptation, distribution and reproduction in any medium or format, as long as you give appropriate credit to the original author(s) and the source, provide a link to the Creative Commons licence, and indicate if changes were made. The images or other third party material in this article are included in the article's Creative Commons licence, unless indicated otherwise in a credit line to the material. If material is not included in the article's Creative Commons licence and your intended use is not permitted by statutory regulation or exceeds the permitted use, you will need to obtain permission directly from the copyright holder. To view a copy of this licence, visit http://creativecommons.org/licen ses/by/4.0/.

\section{References}

Arslan, G. (2018). Social exclusion, social support and psychological wellbeing at school: A study of mediation and moderation effect. Child Indicators Research. https://doi.org/10.1007/ s12187-017-9451-1.

Bergold, S., Kasper, D., Wendt, H., \& Steinmayr, R. (2020). Being bullied at school: The case of highachieving boys. Social Psychology of Education. https://doi.org/10.1007/s11218-019-09539-w.

Blossfeld, H.-P., \& Roßbach, H.-G. (Eds.) (2019). Education as a Lifelong Process: The German National Educational Panel Study (NEPS) (2nd edn, Edition ZfE, Vol. 3): VS Verlag für Sozialwissenschaften.

Bradley, R. H., \& Corwyn, R. F. (2004). Life satisfaction among European American, African American, Chinese American, Mexican American, and Dominican American adolescents. International Journal of Behavioral Development. https://doi.org/10.1080/01650250444000072.

Brüderl, J., \& Ludwig, V. (2014). Fixed-effects panel regression. In H. Best \& C. Wolf (Eds.), The SAGE Handbook of Regression Analysis and Causal Inference (pp. 327-357). 1 Oliver's Yard, 55 City Road, London EC1Y 1SP United Kingdom: SAGE Publications Ltd.

Carlson, M. J., \& Corcoran, M. E. (2001). Family structure and children's behavioral and cognitive outcomes. Journal of Marriage and Family. https://doi.org/10.1111/j.1741-3737.2001.00779.x.

Chang, L., Mcbride-Chang, C., Stewart, S. M., \& Au, E. (2016). Life satisfaction, self-concept, and family relations in Chinese adolescents and children. International Journal of Behavioral Development. https://doi.org/10.1080/01650250244000182.

Chen, S.-Y., \& Lu, L. (2009). Academic correlates of Taiwanese senior high school students' happiness. Adolescence, 44(176), 979-992.

Cheung, F., \& Lucas, R. E. (2014). Assessing the validity of single-item life satisfaction measures: Results from three large samples. Quality of life research : an international journal of quality of life aspects of treatment, care and rehabilitation. https://doi.org/10.1007/s11136-014-0726-4.

Cole, D. A., Jacquez, F. M., \& Maschman, T. L. (2001). Social origins of depressive cognitions: A longitudinal study of self-perceived competence in children. Cognitive Therapy and Research. https://doi. org/10.1023/A:1005582419077.

Credé, M., \& Kuncel, N. R. (2013). Self-reported grades and GPA. In J. Hattie \& E. M. Anderman (Eds.), International guide to student achievement (pp. 49-50). Routledge.

Diener, E. (1984). Subjective well-being. Psychological Bulletin, 95(3), 542-575. 
Diener, E., Oishi, S., \& Lucas, R. E. (2009). Subjective well-being: The science of happiness and life satisfaction. In C. R. Snyder \& S. J. Lopez (Eds.), The Oxford handbook of positive psychology (pp. 187-194). Oxford University Press.

Diener, E., Inglehart, R., \& Tay, L. (2013). Theory and validity of life satisfaction scales. Social Indicators Research. https://doi.org/10.1007/s11205-012-0076-y.

Dweck, C. S., \& Leggett, E. L. (1988). A social cognitive approach to motivation and personality. Psychological Review. https://doi.org/10.1037/0033-295X.95.2.256.

Eccles, J. S., \& Roeser, R. W. (2011). Schools as developmental contexts during adolescence. Journal of Research on Adolescence. https://doi.org/10.1111/j.1532-7795.2010.00725.x.

Edgar, F., Geare, A., Halhjem, M., Reese, K., \& Thoresen, C. (2015). Well-being and performance: Measurement issues for HRM research. The International Journal of Human Resource Management. https://doi.org/10.1080/09585192.2015.1041760.

Eicher, V., Staerklé, C., \& Clémence, A. (2014). I want to quit education: A longitudinal study of stress and optimism as predictors of school dropout intention. Journal of Adolescence. https://doi.org/10. 1016/j.adolescence.2014.07.007.

Feldhusen, J. F., \& Kroll, M. D. (1991). Boredom or challenge for the academically talented in school. Gifted Education International. https://doi.org/10.1177/026142949100700207.

Felsten, G., \& Wilcox, K. (1992). Influences of stress and situation-specific mastery beliefs and satisfaction with social support on well-being and academic performance. Psychological Reports. https:// doi.org/10.2466/pr0.1992.70.1.291.

Fergusson, D. M., McLeod, G. F. H., Horwood, L. J., Swain, N. R., Chapple, S., \& Poulton, R. (2015). Life satisfaction and mental health problems (18 to 35 years). Psychological Medicine. https://doi. org/10.1017/S0033291715000422.

Fischer, L., Rohm, T., Gnambs, T., \& Carstensen, C. H. (2016). Linking the data of the competence tests (NEPS Survey Papers 1). Bamberg.

Fitzenberger, B., Licklederer, S., \& Zimmermann, M. (2015). Übergänge von der allgemeinbildenden Schule in berufliche Ausbildungund Arbeitsmarkt: Die ökonomische Perspektive. In J. Siegfried, S. Seeber, \& B. Ziegler (Eds.), Jahrbuch der berufs- und wirtschaftspädagogischen Forschung 2015 (1st ed., pp. 87-104, Schriftenreihe der Sektion Berufs- und Wirtschaftspädagogik der Deutschen Gesellschaft für Erziehungswissenschaft (DGfE)): Barbara Budrich.

Flett, G. L., Blankstein, K. R., \& Hewitt, P. L. (2009). Perfectionism, performance, and state positive affect and negative affect after a classroom test. Canadian Journal of School Psychology. https://doi. org/10.1177/0829573509332457.

Fredrickson, B. L. (2004). The broaden-and-build theory of positive emotions. Philosophical Transactions of the Royal Society of London. Series B, Biological Sciences. https://doi.org/10.1098/rstb. 2004.1512.

Frey, B. S., \& Stutzer, A. (2002). What can economists learn from happiness research? Journal of Economic Literature. https://doi.org/10.1257/002205102320161320.

Gilman, R., \& Huebner, S. (2003). A review of life satisfaction research with children and adolescents. School Psychology Quarterly. https://doi.org/10.1521/scpq.18.2.192.21858.

Gilman, R., \& Huebner, E. S. (2006). Characteristics of adolescents who report very high life satisfaction. Journal of Youth and Adolescence. https://doi.org/10.1007/s10964-006-9036-.

González, C., Varela, J., Sánchez, P. A., Venegas, F., \& de Tezanos-Pinto, P. (2020). Students' participation in school and its relationship with antisocial behavior, academic performance and adolescent well-being. Child Indicators Research. https://doi.org/10.1007/s12187-020-09761-5.

Grossman, M. (2006). Education and nonmarket outcomes. In E. A. Hanushek \& F. Welch (Eds.), Handbook of the economics of education: Volume 1 (Vol. 1, pp. 577-633). North Holland.

Grunschel, C., Schwinger, M., Steinmayr, R., \& Fries, S. (2016). Effects of using motivational regulation strategies on students' academic procrastination, academic performance, and well-being. Learning and Individual Differences. https://doi.org/10.1016/j.lindif.2016.06.008.

Hascher, T., Morinaj, \& Waber, J. (2018). Schulisches Wohlbefinden: Eine Einführung in Konzept und Forschungsstand. In K. Rathmann \& K. Hurrelmann (Eds.), Leistung und Wohlbefinden in der Schule: Herausforderung Inklusion (pp. 66-82). Beltz Juventa.

Herman, K. C., Lambert, S. F., Reinke, W. M., \& Ialongo, N. S. (2008). Low academic competence in first grade as a risk factor for depressive cognitions and symptoms in middle school. Journal of Counseling Psychology. https://doi.org/10.1037/a0012654.

$\mathrm{Hu}, \mathrm{S} .$, \& Mu, Z. (2020). Some time is better spent than other time: Chinese adolescents' time use and developmental outcomes. Child Indicators Research. https://doi.org/10.1007/s12187-020-09718-8. 
Huebner, E. S. (2004). Research on assessment of life satisfaction of children and adolescents. Social Indicators Research. https://doi.org/10.1023/B:SOCI.0000007497.57754.e3.

Jin, S.-U., \& Moon, S. M. (2016). A study of well-being and school satisfaction among academically talented students attending a science high school in Korea. Gifted Child Quarterly. https://doi.org/10. $1177 / 001698620605000207$.

Jovanović, V. (2016). The validity of the satisfaction with life scale in adolescents and a comparison with single-item life satisfaction measures: A preliminary study. Quality of Life Research : An International Journal of Quality of Life Aspects of Treatment, Care and Rehabilitation. https://doi.org/10. 1007/s11136-016-1331-5.

Kahneman, D., \& Krueger, A. B. (2006). Developments in the measurement of subjective well-being. Journal of Economic Perspectives. https://doi.org/10.1257/089533006776526030.

Kultusministerkonferenz (2019). Das Bildungswesen in der Bundesrepublik Deutschland 2017/2018: Darstellung der Kompetenzen, Strukturen und bildungspolitischen Entwicklungen für den Informationsaustausch in Europa. Bonn.

Kuncel, N. R., Credé, M., \& Thomas, L. L. (2005). The validity of self-reported grade point averages, class ranks, and test scores: A meta-analysis and review of the literature. Review of Educational Research. https://doi.org/10.3102/00346543075001063.

Larson, R. W., \& Richards, M. H. (1991). Boredom in the middle school years: Blaming schools versus blaming students. American Journal of Education, 99(4), 418-443.

Lekholm, A. K., \& Cliffordson, C. (2008). Discrepancies between school grades and test scores at individual and school level: Effects of gender and family background. Educational Research and Evaluation. https://doi.org/10.1080/13803610801956663.

Lyons, M. D., \& Huebner, E. S. (2016). Academic characteristics of early adolescents with higher levels of life satisfaction. Applied Research in Quality of Life. https://doi.org/10.1007/s11482-015-9394-y.

MacCann, C., Lipnevich, A. A., Burrus, J., \& Roberts, R. D. (2012). The best years of our lives?: Coping with stress predicts school grades, life satisfaction, and feelings about high school. Learning and Individual Differences. https://doi.org/10.1016/j.lindif.2011.08.004.

Martin, A. J., Papworth, B., Ginns, P., \& Liem, G. A. D. (2014). Boarding school, academic motivation and engagement, and psychological well-being. American Educational Research Journal. https:// doi.org/10.3102/0002831214532164.

Moore, G. F., Cox, R., Evans, R. E., Hallingberg, B., Hawkins, J., Littlecott, H. J., et al. (2018). School, peer and family relationships and adolescent substance use. Subjective Wellbeing and Mental Health Symptoms in Wales: A Cross Sectional Study. Child indicators research. https://doi.org/10.1007/ s12187-017-9524-1.

Mostafa, T., Gambaro, L., \& Joshi, H. (2018). The impact of complex family structure on child wellbeing: Evidence from siblings. Journal of Marriage and Family. https://doi.org/10.1111/jomf. 12456.

Ng, Z. J., Huebner, E. S., \& Hills, K. J. (2015). Life satisfaction and academic performance in early adolescents: Evidence for reciprocal association. Journal of School Psychology. https://doi.org/10. 1016/j.jsp.2015.09.004.

Nordlander, E., \& Stensöta, H. O. (2014). Grades - For better or worse?: The interplay of school performance and subjective well-being among boys and girls. Child Indicators Research. https://doi.org/ 10.1007/s12187-014-9233-y.

Ocal, A., \& Altınok, A. (2016). Developing social sensitivity with service-learning. Social Indicators Research. https://doi.org/10.1007/s11205-015-1091-6.

Park, N. (2004). The role of subjective well-being in positive youth development. The Annals of the American Academy of Political and Social Science. https://doi.org/10.1177/0002716203260078.

Pekrun, R., Elliot, A. J., \& Maier, M. A. (2006). Achievement goals and discrete achievement emotions: A theoretical model and prospective test. Journal of Educational Psychology. https://doi.org/10. 1037/0022-0663.98.3.583.

Pomerantz, E. M., Altermatt, E. R., \& Saxon, J. L. (2002). Making the grade but feeling distressed: Gender differences in academic performance and internal distress. Journal of Educational Psychology. https://doi.org/10.1037//0022-0663.94.2.396.

Powdthavee, N., Lekfuangfu, W. N., \& Wooden, M. (2015). What's the good of education on our overall quality of life? A simultaneous equation model of education and life satisfaction for Australia. Journal of behavioral and experimental economics, https://doi.org/10.1016/j.socec.2014.11.002.

Pribesh, S., \& Downey, D. B. (1999). Why are residential and school moves associated with poor school performance? Demography. https://doi.org/10.2307/2648088. 
Proctor, C. L., Linley, P. A., \& Maltby, J. (2009). Youth life satisfaction: A review of the literature. Journal of Happiness Studies. https://doi.org/10.1007/s10902-008-9110-9.

Rathmann, K., Herke, M., Bilz, L., Rimpelä, A., Hurrelmann, K., \& Richter, M. (2018). Class-level school performance and life satisfaction: Differential sensitivity for low- and high-performing school-aged children. International Journal of Environmental Research and Public Health. https:// doi.org/10.3390/ijerph15122750.

Reysen, R. H., Degges-White, S., \& Reysen, M. B. (2017). Exploring the interrelationships among academic entitlement, academic performance, and satisfaction with life in a college student sample. Journal of College Student Retention: Research, Theory \& Practice, . https://doi.org/10.1177/15210 25117735292.

Ryan, R. M., \& Deci, E. L. (2000). Self-determination theory and the facilitation of intrinsic motivation, social development, and well-being. American Psychologist. https://doi.org/10.1037//0003-066X. 55.1 .68 .

Scharl, A., Fischer, L., Gnambs, T., \& Rohm, T. (2017). NEPS Technical Report for Reading: Scaling Results of Starting Cohort 3 for Grade 9 (NEPS Survey Papers 20). Bamberg.

Schmitt, N., Oswald, F. L., Friede, A., Imus, A., \& Merritt, S. (2008). Perceived fit with an academic environment: Attitudinal and behavioral outcomes. Journal of Vocational Behavior. https://doi.org/ 10.1016/j.jvb.2007.10.007.

Smith, T. W. (1995). Some aspects of measuring education. Social Science Research, 24(3), $215-242$.

Smith, C., \& Carlson, B. E. (1997). Stress, coping, and resilience in children and youth. Social Service Review. https://doi.org/10.1086/604249.

Steinhauer, H. W., \& Zinn, S. (2016). NEPS Technical Report for Weighting: Weighting the Sample of Starting Cohort 3 of the National Educational Panel Study (Waves 1 to 5). Bamberg.

Steinmayr, R., \& Meißner, A. (2013). Zur Bedeutung der Intelligenz und des Fähigkeitsselbstkonzeptes bei der Vorhersage von Leistungstests und Noten in Mathematik. Zeitschrift für Pädagogische Psychologie. https://doi.org/10.1024/1010-0652/a000113.

Sticca, F., Goetz, T., Bieg, M., Hall, N. C., Eberle, F., \& Haag, L. (2017). Examining the accuracy of students' self-reported academic grades from a correlational and a discrepancy perspective: Evidence from a longitudinal study. PLoS One. https://doi.org/10.1371/journal.pone.0187367.

Suldo, S. M., Shaffer, E. J., \& Riley, K. N. (2008). A social-cognitive-behavioral model of academic predictors of adolescents' life satisfaction. School Psychology Quarterly. https://doi.org/10.1037/ 1045-3830.23.1.56.

Suldo, S. M., Thalji-Raitano, A., Hasemeyer, M., Gelley, C. D., \& Hoy, B. (2013). Understanding middle school students life satisfaction: Does school climate matter? Applied Research in Quality of Life. https://doi.org/10.1007/s11482-012-9185-7.

Suldo, S. M., Riley, K. N., \& Shaffer, E. J. (2016). Academic correlates of children and Adolescents' life satisfaction. School Psychology International. https://doi.org/10.1177/0143034306073411.

Valiente, C., Swanson, J., \& Eisenberg, N. (2012). Linking students' emotions and academic achievement: When and why emotions matter. Child Development Perspectives. https://doi.org/10.1111/j. 1750-8606.2011.00192.x.

van de Ham, A.-K., Schnittjer, I., \& Gerken, A.-L. (2018). NEPS Technical Report for Mathematics: Scaling Results of Starting Cohort 3 in Grade 9 (NEPS Survey Papers 38). Bamberg.

Vansteenkiste, M., Ryan, R. M., \& Soenens, B. (2020). Basic psychological need theory: Advancements, critical themes, and future directions. Motivation and Emotion. https://doi.org/10.1007/ s11031-019-09818-1.

Weinert, S., Artelt, C., Prenzel, M., Senkbeil, M., Ehmke, T., \& Carstensen, C. H. (2011). 5 development of competencies across the life span. Zeitschrift für Erziehungswissenschaft. https://doi.org/10.1007/ s11618-011-0182-7.

Willingham, W. W., Pollack, J. M., \& Lewis, C. (2002). Grades and test scores: Accounting for observed differences. Journal of Educational Measurement. https://doi.org/10.1111/j.1745-3984.2002.tb011 33.x.

Winship, C., \& Mare, R. D. (1992). Models for sample selection Bias. Annual Review of Sociology, 18, 327-350.

World Health Organization (2018). Adolescent mental health in the European Region. https://www.euro. who.int/_data/assets/pdf_file/0005/383891/adolescent-mh-fs-eng.pdf. Accessed 11 Jan 2021. 
World Health Organization (2019). Mental Health: Fact Sheet. https://www.euro.who.int/en/health-top$\mathrm{ics} /$ noncommunicable-diseases/mental-health/data-and-resources/fact-sheet-mental-health-2019. Accessed 11 Jan 2021.

Publisher's Note Springer Nature remains neutral with regard to jurisdictional claims in published maps and institutional affiliations. 